\title{
Foreword to Special Topic Section on the Interface of Positive Psychology with Rehabilitation Research and Practice
}

\author{
Brian T. McMahon ${ }^{1}$ Jeong Han Kim ${ }^{1}$
}

Published online: 29 December 2015

(c) Springer Science+Business Media New York 2015

To hear adherents of positive psychology tell it, the advent of positive psychology can be traced back to 1998. At Martin E. P. Seligman's Presidential Address to the American Psychological Association, he described a profession which “... largely neglected the latter two of (psychology's) three pre-World War II missions: curing mental illness"; helping all people to lead more productive and fulfilling lives; and identifying and nurturing high talent. Seligman resolved to use his APA presidency to initiate a shift in psychology's focus toward a more positive psychology" [1]. Other historians have noted that positive psychology began well before 1998 and have given due credit to earlier contributors [2].

Few would question that the resurgence of interest and momentum in positive psychology is in full swing. Without detracting from the considerable achievements of our contemporaries, contributors to this special issue are mindful that positive psychologists have been active even dating back to World War I and its aftermath. The theoretical and applied contributions of Alfred Adler, Victor Frankl, Carl Rogers, Abraham Maslow, William Glasser and others are matters of record. Linley [1] noted as early as 1946-1947 that the Veterans Administration and the National Institute of Mental Health had configured psychology as a healing discipline based upon a disease model and illness ideology. But even then and ever since, large segments of counseling psychology in particular have consistently rejected the medical model and posited a more holistic approach. Their collective body of work merits close examination and revisionist history should not purge

Brian T. McMahon

btmcmaho@vcu.edu

1 Virginia Commonwealth University, Richmond, VA, USA this foundation from our training or traditions. Indeed there exists today considerable evidence of its effectiveness; e.g., common factors research [3].

Regarding rehabilitation, as early as 1978 Warren Rule wrote about the applications of Adlerian lifestyle counseling with emphasis on the innately social nature of clients, consciousness, health and normality, purposeful behavior, self-perception, and competition [4]. Frankl and Rogers underscored active involvement of the client, capacity for growth, basic goodness of human nature, insight and change, independence and integration, focus upon the affective, client responsibility, counselor acceptance and tolerance and the uniqueness and wholeness of each individual. Glasser stressed achievement, meaning and purpose, personal responsibility and the need to love and be loved. Frankl observed that life affords both meaning and the freedom to pursue it under all circumstances. Maslow sought to document the characteristics of the "growing tip" of society and discovered universal needs which for some, if fulfilled, may lead to self-actualization. Each of these legends believed that psychology was misdirected in its obsession with psychopathology and contributed mightily to our current understanding of what constitutes mental health. Each rejected labelling and the stigmatization resulting from rigid psychiatric diagnoses. Each perceived mankind as inherently good and highly individualized in terms of personality. Their thinking did result in calls for action and lead to de-institutionalization which, although neither well planned nor executed, were advanced by Szaz, Wolfensberger, and others. Positive psychology was not as popular as it is in the new millennium, but its influence was enduring.

In the context of a civil rights movement in the 50s and 60s there emerged a parallel movement in the broader disability community for self-determination and equal 
treatment under the law. This community included disability advocacy organizations, rehabilitation professionals, policy makers and academics. They began to coalesce around a set of principles which came to be known as independent living or rehabilitation philosophy. These tenets formed the basis for a long history of major federal laws which resulted in more resources, policies and enforcement mechanisms for their realization. Enactments of these laws began with the Smith Hughes Act in 1917 and continue today with the Americans with Disabilities Act Amendments of 2008. The principles include self-determination, societal contribution, holistic approach to rehabilitation, focus on residual assets and capabilities, the intrinsic value of each human being, environmental restructuring to fit people, dignity of risk, transdisciplinary team functioning, normalization, reality factors, criterion of ultimate functioning, and coping and adaptation.

For readers of this journal and rehabilitation professionals of all stripes (allied health professionals, rehabilitation nurses and psychologists, rehabilitation counselors and physiatrists, rehabilitation engineers and assistive technologists, occupational health professionals, disability managers, providers of disability support services in higher education, developers of adaptive equipment, case managers), Whitehouse had you in mind when in 1961 he declared:

Rehabilitation is primarily and fundamentally a therapeutic philosophy that is generic to the whole treatment field. Each profession utilizes this common philosophy through the operations characteristics of its training and knowledge. All professions owe allegiance to the general principles, but each applies them through its own special practice skills (p.20).

In rehabilitation counseling, each of these principles is instilled deeply into the pre-professional training of all graduate students. On-the-job training underscores how each principle comes to life in every-day decision making in the execution of both clinical and administrative duties. This is reinforced by the infusion of these principles into certification, accreditation and licensing standards; codes of ethics; standards of practice; and/or continuing education requirements in all rehabilitation disciplines. These common principles facilitate communication between the disciplines, and enable consensus to be reached regarding individualized rehabilitation plans.

For purposes of this special issue section, the reader is asked to gauge the extent to which rehabilitation principles are reflected in the articles which follow, and how consistent these are with the underlying assumptions of modern positive psychology: Wisdom (inter-professional teams); Courage (dignity of risk; societal contribution);
Humanity (individualization; and whole person); Justice (normalization; self-determination); Temperance (criteria of ultimate functioning, reality factors); and Transcendence (intrinsic value; coping and adaptation).

Our message is to affirm that positive psychology has risen to the forefront due to a new generation of leaders, and with a manifest commitment to an evidence-based resurgence. Our second message is to affirm that the foundation of many rehabilitation disciplines is largely rooted in positive psychology. Rehabilitation has steadfastly adhered to the same philosophical spirit, and has to some extent sustained it during times of dormancy. Rehabilitation researchers have in place some very welcoming laboratories in which positive psychology innovations can be developed and tested.

This is demonstrated in the articles that follow directly. Each is written by a team of experienced rehabilitation researchers and practitioners from a variety of disciplines. They cover topics ranging from history, theoretical development, and measurement of constructs to demonstrations of the applications of positive psychology in rehabilitation practice. They are carefully sequenced to maximize learning, however each can be enjoyed as a "stand alone" reading. Professors Livneh and Martz begin the procession by comparing and contrasting both the theoretical and research perspectives of rehabilitation and positive psychology and provide some useful suggestions for researchers eager to study at this intersection. Next, the same duo summarizes the empirical findings on the relationships between six selected positive psychology constructs and those outcome measures indicating adaptation to disability.

In the feature article, Professor Kim and his colleagues use theory building methodology to create a Virtue-based Model of Psychosocial Adaptation to Chronic Illness and Disability. The model provides heuristic value and structure to the future exploration of positive psychology interventions toward rehabilitation goals. Professor Kim then leads a second team to develop the Adapted Inventory of Virtues and Strengths for the assessment of rehabilitation clients. Finally, a example is provided by Mills and her colleagues who review the literature to generate ten positive psychology measures and interventions with the potential for improving the emotional, social, and cognitive functioning for vocational rehabilitation clients with TBI.

The resurgence of positive psychology will bring about even more progress for both the rehabilitation disciplines and the civil rights movement for Americans with disabilities. We thank our authors, editors, and readers for this opportunity to play a small but positive role in these developments. 


\section{References}

1. Linley PA, Joseph S, Harrington S, Wood AM. Positive psychology: past, present, and (possible) future. J Pos Psych. 2006;1:3-16.

2. McCullough ME, Snyder CR. Classical sources of human strength: revisiting an old home and building a new one. J Soc Clin Psych. 2000;19:1-10.
3. Hubble MA, Duncan B, Miller SD, Wampold BE. In: Duncan BL, Miller SD, Wampold BE, Hubble MA, editors. The heart and soul of change: delivering what works in therapy, 2nd ed. Washington, DC: American Psychological Association; 2010. p. 23-46.

4. Rule W, Bishop M. Adlerian lifestyle counseling: practice and research. New York: Taylor and Francis Group; 2006. 